\title{
EDUCADOR(A) INTERCULTURAL NUMA PERSPECTIVA DE FORMAÇÃO AMBIENTALIZADA E DESCOLONIALIZANTE
}

\author{
João Batista de Albuquerque Figueiredo* \\ Maria Eleni Henrique da Silva**
}

Resumo: Este estudo objetiva apresentar uma proposta de formação de educador@ambiental popular capaz de responder aos dilemas da modernidade/colonialidade por meio do diálogo entre a Educação Intercultural, Educação Popular e a Educação ambiental. Ele se justifica no desvelar da modernidade/colonialidade, na qual houve um distanciamento na relação humano-humano e humano-'natureza. E, ao afetar criticamente a dimensão social e ecológica, traz implicações para a própria formação dess@s educadore@s. Algumas questões nos mobilizam: o que podemos entender por modernidade? O que isto implica para a educação e para os modos de operar essa formação? Podemos pensar em alternativas a este padrão educativo no tocante a formação de educador@s ambientais populares que atendam aos dilemas do mundo atual? Em busca de respostas mobilizadoras de ações potencialmente transformadoras, realizamos uma pesquisa bibliográfica dialógica. Estabelecemos um diálogo entre Educação Intercultural, Educação Popular, Educação Ambiental, Formação de Educador@s e os Estudos da Colonialidade/Modernidade. Concluímos com uma proposta que resulta na Formação Relacional Ambientalizada Descolonializante.

Palavras-chave: Educação Popular. Educação Intercultural. Formação Relacional. 


\title{
EDUCATOR (A) POPULAR IN PERSPECTIVE TRAINING AND AMBIENTALIZADA DESCOLONIALIZANTE
}

\begin{abstract}
This study aims to present a proposal for the formation of an educator (a) environmental popular able to answer to the dilemmas of modernity / coloniality through dialogue between the Popular Education and Environmental Education. He justified the unveiling of modernity / coloniality, in which there was a gap in the relationship human-human and human-'nature'. And, critically affect the social and ecological, has implications for the proper formation of these educators. Some questions move us: What do we understand by modernity? What this implies for education and modes of operating at this training? We can think of alternatives to this standard education regarding environmental educator training that meet the popular dilemmas of today's world? In search of answers mobilizing actions potentially transformative, dialogic conducted a literature search. We establish a dialogue between Intercultural Education, Popular Education, Environmental Education, Educator Training and Studies of Coloniality / Modernity. We conclude with a proposal that results in the formation Relational Ambientalizada Descolonializante.
\end{abstract}

Keywords: Popular Education. Intercultural Education. Training Relational. 
No início era o verbo. O verbo estava com Deus. E assim começa tudo. Interessante refletir acerca desse trecho inicial da Gênese, livro sagrado que retrata a saga de muitos povos da antiguidade na busca de sua caracterização, daquilo que lhes distingue e identifica.

Este é outro interessante aspecto associado a história dos povos. Em geral, temos um movimento de constituição de sua "identidade". E esta regularmente ocorre em contraposição a outros povos. De modo semelhante ocorre com os indivíduos no contexto social, na ambiência da vida. Habitualmente os seres se constituem por meio de suas diferenças, embora as semelhanças sejam contempladas quando se pretende arregimentar forças ou quando se quer adquirir maior poder.

O verbo tem sido cada vez mais e mais um artifício de poder e de definição identitária. $\mathrm{O}$ verbo nos tempos atuais vem substituindo inclusive a própria realidade ao se confundir com a mesma por meio das representações, dos símbolos e ícones que adquirem o status de retrato real da realidade. Incrível como isto se fortalece por meio dos veículos midiáticos em geral e, em particular, dos que se encontram a serviço da colonialidade.

Estamos imersos em um cenário Colonializante Moderno (QUIJANO, 1991, 2005; LANDER, 2005), capitalista, neoliberal, eurocêntrico, mecanicista, fragmentador, ideologizante, hiperveloz, centrado no mercado, no produto, no consumo, no lucro. Traz como consequência que lhe alimenta, por sua vez: Relações DESHumanas; Colonialização, representação enquanto realidade; Ideologia do mercado acima da vida.

Assim, na contramaré desse movimento ainda tão forte este trabalho busca o fruto de uma articulação entre e Educação Intercultural (EI), Educação Popular (EP) e a Educação ambiental (EA). Justifica-se no desvelar que, em virtude da modernidade/ 
colonialidade, houve um distanciamento na relação humano-humano e humano-'natureza'. E, ao afetar criticamente a dimensão social e ecológica, se propaga para outras áreas do existir humano, tal como a educação, a própria formação de educador@s ${ }^{1}$. Isto compulsoriamente traz implicações para os processos educativos.

Desse modo, é pertinente pensar uma proposta na qual trazemos como pressuposto a essencialidade da EP dialogar com a EA e a EI, com os processos formativos, e, assim, contribuir para uma reaproximação destas relações que foram, de certo modo, comprometidas pela lógica hegemônica, semente-fruto da colonialidade/modernidade.

Diante dos objetivos explicitados, algumas questões nos mobilizam: o que podemos entender por este modelo societário denominado de modernidade por alguns? Qual o seu significado? O que isto implica para a educação e para os modos de operar a formação de educador@s? Podemos pensar em alternativas a este padrão educativo no tocante a formação de educador@s intercultural que contemple motes importantes para avançar com este entendimento e materializar estratégias e práticas-refletidas que atendam aos dilemas do mundo atual?

Em busca de respostas mobilizadoras de ações potencialmente transformadoras, realizamos uma pesquisa bibliográfica dialógica. Fomos a busca dos Estudos da Colonialidade/Modernidade (ECM). Vimos também que se fazia urgente problematizar a educação bancária, opressora, colonializante, tão ao gosto da modernidade corporificada pela sociedade atual. Para isto buscamos Paulo Freire e suas importantes contribuições no sentido de pensar processos educativos que estivessem sincronizados com o desvelamento desse corpo social colonializado, portanto proposto por meio da lógica popular, dos saberes populares. Ainda mais, 
observamos a pertinência vital do destaque às temáticas ecológico-ambientais e socioambientais para agir em consonância com um possível futuro desejável para a humanidade. Para atender a esta intenção, fomos dialogar com a Educação Ambiental. Finalmente, problematizamos a formação de educador@s que ainda predomina no mundo contemporâneo.

Assim, avançamos com esta reflexão fundamentada nas ações pedagógicas que se apresentam diante de nossos olhares curiosos que perscrutam o cenário da formação atual. Neste relance, que se aprofunda dentro de limites evidentes, postados pelas circunstancias da observação, pelo contexto da pesquisa, pelas relações metodológicas e, mesmo, pelas escolhas epistemológicas, podemos constatar certa fragilidade na formação quanto ao trato da temática ambiental, bem como de fundamentos relativos a uma educação mais contextualizada, democrática, popular. Por isto, esta ideia de um diálogo entre a Formação, a EI, a EP e a EA.

Com esta base de entendimento, vamos percorrer um trajeto que possa ampliar nossa reflexão e potencializar alternativas didático-pedagógicas que avancem com estas contenções inerentes ao ambiente constituído pela modernidade/colonialidade, a Formação do educador@, a EI, a EP, suas matrizes crítica, progressista e de direita, e a EA crítica e dialógica.

\section{A modernidade e a colonialidade é o cenário atual que poten-} cializa o diálogo pretendido neste artigo, daí optamos por entender, minimamente, o que significa 'modernidade' como contexto no qual identificamos os graves dilemas em questão e as crises aqui denunciadas, por afetar a educação em geral e, em particular, a EP, a EA e a própria Formação de Educador@s.

Neste intuito, lembramos que a modernidade científica se identifica com o cartesianismo, no fomento de valores tais como a uni- 
formização do conhecimento pelo método científico com o uso de instrumentos tais como a: fragmentação - análise; mecanicismo - linearidade; previsibilidade - controle; entender para dominar; negação; cognitivismo; neutralidade do pesquisador; competitividade - exclusão; a negação do corpo.

É possível perceber com o avanço da modernidade, que alguns denominam de pós-modernidade, que se agravam alguns desses problemas e sutilizam-se outros. Tal como ocorre ao se reordenar as fronteiras das Nações na ampliação do modo como se produz riqueza; ao pulverizar ainda mais a produção e expandir o consumo. Há uma urgência que alimenta os processos sociais; uma vaporização dos laços sociais; uma perda do valor da história, das narrativas, do bem-estar social; transferência do poder do Estado às Grandes Corporações Comerciais e Financeiras. Parece-nos mais apropriado nominar esta ambiência de hipermodernidade (LIPOVETSKY, 2004), de modernidade volátil (BAWMAN, 2001), ao invés de pós-modernidade.

Temos ainda problemas resultantes na educação: a civilização técnico-científica invade a escola desapropriando outras formas de conhecer e aprender; multiplicidade e quantidade associada à infinidade de informações disponíveis que geram incongruências e interpretações múltiplas e dúbias; há um relativismo fundamental generalizado; temos, porém, um único conhecimento válido, uma única forma de elaborar conhecimento, uma cultura válida que invalida as demais; uma fratura entre educação formal e vida comunitária; uma desvalorização dos conhecimentos e saberes de experiência feitos; lógica do vigiar e punir; excluir e privilegiar, hierarquizar e competir manifesta no ambiente escolar; o currículo é definido em instâncias dissociadas das escolas e imposto como determinação disciplinar etc. 
Consideramos, frente a este desafio de superar a modernidade e suas sequelas, a necessidade de outras leituras, outros caminhos, paradigmas, neste caso frente a educação e a formação. Necessidade de outro trânsito entrecruzando os campos disciplinares, na tentativa de contemplar a multiplicidade do mundo, que insiste em escapar por entre os vãos das grades curriculares. Os passos da Transversalidade são potentes, pois que implicam numa postura que rompe com a hierarquia de saberes (vertical e horizontal). Há de se ter outra subjetividade compartilhada e integrativa na qual a afetividade/amorosidade é incorporada.

Efetivamente existem diversas maneiras de estudar o tema 'modernidade'. A Colonialidade, perspectiva originalmente cunhada por Aníbal Quijano (1991), é uma das mais amplas e, para nós, representa relevante contribuição porque sinaliza para o modelo hegemônico de sociedade que se instituí através do domínio colonial, pautado no capitalismo.

Para entender esta proposição analítica, começamos por explicitar a diferença entre Colonialismo e Colonialidade. Colonialismo significa invadir, dominar, exercer supremacia sobre @outr@ no contexto material. Colonialidade, por sua vez, retrata o colonialismo acrescido do domínio sobre a dimensão do imaginário, das ideologias. A Colonialidade informa que temos um processo ainda mais perverso de colonizar as mentes, ideias, imaginário, culturas.

Os Estudos da Colonialidade/Modernidade potencializam uma crítica ao modelo de sociedade planetária pautada na hierarquização humana que justifica a exploração de outro ser humano como se fosse uma coisa sem alma. Fundamentam uma crítica ao eurocentrismo e à sua episteme que opera separações sucessivas e reducionismos vários (LANDER, 2005). Podemos estudar a Coloniali- 
dade por meio de quatro eixos de investigação: a colonialidade do poder, do saber, do ser e do conviver (da mãe natureza).

Quijano, ao tratar da Colonialidade do Poder, afirma que esta se manifesta por meio da ideia de "raça" como fundamento do padrão universal de classificação e de dominação social; o capitalismo, como padrão universal de exploração; o Estado-Nação como forma central de controle da autoridade coletiva; o Eurocentrismo como forma hegemônica de regulação da subjetividade/intersubjetividade, em particular no modo de produzir conhecimento.

Entendemos que, para Quijano, a Colonialidade do Saber, implica no romper epistemológico entre 'res extensa' e 'res cogitans', razão e subjetividade; na cisão entre razão e mundo sem razão; na ruptura ontológica entre mente e mundo, humanos numa postura instrumental frente ao mundo; entre ciência e senso comum; entre o universal e o resto, civilizado e barbárie. Trata do Eurocentrismo como a perspectiva única do conhecimento.

Destaco que a educação colonializante se consolida na modernidade e garante o estado atual da sociedade humana. A colonialidade do saber mantém sua garantia por meio das instituições formadoras, educativas, que a sociedade moderna materializou para assegurar este perverso projeto subalternizante e opressor.

\section{É possível identificar duas dimensões constitutivas do me-} tarrelato da modernidade que contribuem para explicar sua eficácia opressora: a primeira refere-se às sucessivas partições do mundo "real". A segunda é a forma como se articulam estes saberes com a organização do poder, especialmente as relações coloniais/ imperiais de poder constitutivas do mundo moderno.

Podemos tentar entender também a Colonialidade do Ser como um rompimento entre espiritualistas e 'ateus' (indígenas da América Latina), definidora de uma separação entre humanos e 
aqueles que passam a ser considerados não humanos, por se tratarem neste corpo político-epistêmo-sócio-ecológico, como seres sem alma; potencializa a coisificação do ser humano. Este passa a ser objeto de consumo e agente de produção. Esta colonialidade se exerce por meio da inferiorização, des-humanização.

Com a ajuda de Walsh (2008), apoiada por Lander, Mignolo e Coronil, refletimos acerca da colonialidade do conviver, denominada por esta parceira de 'Colonialidad de la madre naturaleza y de la vida misma'. Ela afirma que esta colonialidade ocorre ao se dissociar razão, cultura, sociedade e natureza.

A Colonialidade do conviver cria o impossível, o humano dissociado da natureza, na divisão natureza/sociedade. Descarta o mágico-espiritual-social; relação milenar entre mundos biofísico, humano e espiritual, incluindo o dos ancestrais; sustentação de vida e da humanidade mesma (WALSH, 2008).

Os impactos das ações colonializantes afetam todos os segmentos planetários. A colonialidade compromete política, economia, cultura, ecologia, ciência, arte, religiosidade, relações cotidianas, familiares e sociais em geral. E, ao afetar as relações de poder ressoa intensamente nas relações de saber. A colonialidade possui uma dimensão macro-colonializante, identificada com as grandes dimensões da sociedade, tanto quanto micro-colonializante, relacionada às dimensões do cotidiano, das relações face a face.

A micro-colonialização, em sua capilaridade, implica num dispositivo opressor, des-humanizante. Acontece sutilmente das mais diversas formas; se invisibiliza no cotidiano; se expande para todos os recantos; se manifesta por meio da maioria das pessoas e encontra reforço nos meios de comunicação, no sistema educacional, nos lugares de elaboração de conhecimento, nas praças, ruas, instituições, empresas, nas conversas cotidianas. 
Seu principal meio de operação ocorre através da desqualificação d@outr@.Utiliza como procedimento doutrinal a formulação de princípios, regras, mitos, ídolos, crenças, modas, padrões que definem o bom, o bem, o belo, o aceitável, o culto, desde uma externalidade constituída por uma lógica impositiva que se torna hegemônica. Tudo isto afeta os processos formativos, a educação.

Com a consolidação da Colonialidade avançada, que se manifesta juntamente com a hegemonia estadunidense, podemos considerar que se institui, na sociedade, um conjunto de mecanismos de vigilância que potencializam os processos disciplinares (FOCAULT, 1989). Com o avançar da modernidade se institui uma espécie de sociedade do controle (DELEUZE, 1992). Nela o poder cancerígeno da colonialidade adquire mais pujança. A capilarização desse processo ocorre por meio do controle, da invasão cultural, política, econômica, social manifesta em todos os lugares invisivelmente. O disciplinamento ocorre via hierarquização, modelização, medo, controle da subjetividade; se torna volátil e não localizado.

A micro-colonialidade estrategicamente esvazia a imagem da sua virtualidade, dando à informação um ar de verdade inconteste. Desse modo a representação se confunde com o próprio acontecimento. Isto potencializa a ideologia de um olhar onipresente, sob o qual tudo se passa e nada é despercebido. Tal como se fossemos habitantes de um mundo vigiados continuamente. O que se dá principalmente por intermédio da mídia em geral.

Desvelado este contexto é possível elaborar um texto descolonializante, intercultural crítico. Para isto consideramos a dimensão educativa privilegiada. A educação efetiva uma interface entre o macro e o micro social. Na formação se tem uma potência de investir em transformações necessárias e desejáveis para a socieda- 
de. Neste caso, afirmamos a premência de ações formadoras descolonializantes que se contraponham a esta micro-colonialidade. Daí a importância de incorporar alternativas de formação. Assim propomos acolher as contribuições oriundas do diálogo entre a EI, EA e EP.

Faz-se premente uma retomada do poder da educação libertadora. Isto implica num reordenamento das relações entre educação, comunidade, comunicação, formação, de modo que o ato de educar possa ser revisto no âmbito da interação educador@-educand@, como potente na superação da micro-colonialidade que se alimenta da educação bancária. Portanto, uma educação dialógica carrega poder de desvelar esta opressão e reintegra o ser humano no ambiente de saberes relacionais, interculturais críticos, habilitadores de leituras críticas e libertadoras, na direção de uma sociedade descolonializada, contextualizada, ambientalizada.

A crítica à Colonialidade/Modernidade, proposta por Lander (2005), é exemplificada no campo educativo ao se eleger o perfil do "bom aluno", caracterizado por uma inteligência lógico-cognitiva aguçada; uma postura fria e calculista; uma atitude competitiva e excludente; pela capacidade de armazenamento mnemônico.

A ação educativa colonializante impõe o cientificismo eurocêntrico; o controle da subjetividade/intersubjetividade; uma única forma válida de conhecimento, de aprendizagem, portanto, de formatações que ocorrem na educação.

$\mathrm{Na}$ colonialidade do saber também se encontra presente, como reforço e como princípio, a colonialidade da natureza, pois que ela contribui para esta fragmentação epistêmica e ontológica ao reduzir o mundo a um armazém, um estoque disponível para os exploradores, no sentido capitalista do termo. 
A Colonialidade da Natureza justifica, em certa medida, a propriedade e posse de bens decorrentes da exploração concreta e da exploração virtual que ocorre por meio da manipulação cibernética da pseudo-riqueza que é o dinheiro, símbolo que substituiu seu suporte concreto. Concomitantemente se justifica a dessacralização da vida, da natureza não humana e acirra-se a coisificação dos que não se alinham com a modernidade/colonialidade.

DesColonializAção é a ação de superar a opressão. Podemos propô-la por meio de uma releitura de Paulo Freire aplicada a formação do educador, numa reflexão acerca da Educação Ambiental Popular Intercultural Crítica. Saliento que o ser humano é um ser de natureza, social e cultural. E a interface privilegiada de integração dessas dimensões, nos parece, ser a educação. É neste lócus privilegiado que encontramos melhores condições de intervir numa postura contra-hegemônica, como estratégia de superação da colonialidade.

Ao atuar nas bases que sustentam a colonialidade do poder, amparada essencialmente pela colonialidade do saber, a educação, a ciência e a cultura podem habilitar dispositivos transgressores, desveladores da lógica colonializante da educação bancária, que se transveste de diversas formas. Respaldado por este caminho, propomos a Teoria da Ação Dialógica para a formação do intercultural, popular, integrada à ambientalizAção, contributo importante para a DesColonializAção.

\section{A reflexão dialogal entre Educação Intercultural (EI), Edu-} cação Popular (EP) e a Educação Ambiental (EA) ajuda para que possamos subsidiar nossa proposta de uma formação relacional crítica de educador ambiental popular intercultural. Neste trajeto, buscamos uma proposta de EA que se identifique com EP, 
particularmente dialógica, Paulofreireana. Por isto escolhemos a Educação Ambiental Dialógica (EAD) (FIGUEIREDO, 2007).

Para caracterizar nossa opção, apresentamos as potencialidades do diálogo entre a EI, EP e a Educação Ambiental para contribuir com a superação dos 'danos' advindos da colonialidade /modernidade. Com este propósito, mesmo sem o intuito de apresentar uma retrospectiva histórica, ou mesmo uma caracterização da EP, acreditamos pertinente selecionar elementos dela que se nos apresentam como importantes aos processos formativos de educador@s, populares, ambientais, interculturais, críticos.

Começamos por informar que a educação popular se firma sob esta terminologia em meados da década de 1950 a 1960. Para Brandão (1986), foram marcantes para o seu surgimento: a chegada ao poder de governos populistas, em vários países latino-americanos; a organização e engajamento de grupos nas lutas populares, advindos dos setores médios da sociedade que pertenciam à intelectualidade universitária e estudantil, religiosa e militante; a ampliação de espaços dos movimentos populares e o surgimento de formas de organização popular.

Ainda segundo Brandão (1986), este primeiro momento se apresenta como um movimento pedagógico que objetivou refletir sobre a educação das camadas populares, uma espécie de educação popular que se constitui como movimento popular que incorpora o movimento pedagógico, uma educação constituída para e pelo povo. Ele afirma que a EP surge como proposta por se vincular organicamente com a criação de saberes populares, instrumentos de nova hegemonia.

Importante destacar que a formação aqui refletida objetiva uma qualificação de educador@s populares para que possam atuar tan- 
to fora quanto no contexto escolar. Assim, entendemos que a EP se apresenta como uma alternativa no âmbito educacional, político e pedagógico e que seus pressupostos podem ser difundidos para outros campos, incluindo a formação docente.

Lembramos que, em seus primeiros passos, a EP se viu ameaçada em virtude da implantação em diversos países da América Latina de ditaduras militares, tal como a que ocorreu no Brasil, na década de 1960. Desse modo, as tentativas de organização dos grupos para o fortalecimento e difusão dos pilares da educação eminentemente política e voltada para@s oprimid@s, foram nesta época. Este quadro se modifica no final da década de 1970 e início da década de 1980, quando a EP ganha força ao tornar-se uma prática com dimensões político-educativa. Em 1990 ocorre um período de declínio ou amansamento da EP, marcado pela redemocratização burguesa. Aí surgem, tal como ocorreu com a EA, propostas identificadas com outras referências políticas, algumas até opostas ao compromisso com o povo.

A história da educação popular é a história de enfrentamentos aos projetos expressos pela classe hegemônica. As diferentes experiências de EP nasceram e tinham razão de existência no conflito político diante da opressão. Ela traz como um dos seus princípios a valorização da cultura popular, dos saberes populares, do contexto no qual vivem os grupos populares. Trata-se de uma corrente pedagógica e um movimento cultural (CARRILO, 2007). Ela reconhece e assume as atuais demandas das sociedades (WANDERLEY, 2010).

Podemos assim dizer que uma das especificidades da EP é a contextualização e, podemos pensar na ambientalização, uma vez que parcela das necessidades, de informações, conhecimentos e 
saberes são intrínsecos aos que nas camadas populares vivem e convivem.

Pensar uma proposta de formação para EP ou partir dela, implica em assumir uma postura comprometida com a denúncia diante de um modelo de sociedade que vive sob a égide da colonialidade; com a anunciação de possibilidades de descolonialização. Assim, faz-se oportuno pensar ações, experiências educativas incorporadas vividamente pel@s envolvid@s, levando-se em conta seusconhecimentos, a dinâmica relacional, amorosa; as relações com o ambiente, com o lugar, incorporadas de modo a potencializar que os indivíduos empoderem-se com os vínculos que possuem consigoecom@soutr@.

A EP Freireana (EPF), em sua dinâmica que inclui a participação e inclusão, de forma democrática, autônoma, interdependente, traz o potencial para estabelecer uma reflexão crítica sobre os problemas e suas soluções, como se estes fossem (e são) do coletivo, do qual cada um faz parte e nele está contido.

Reafirmamos que um dos principais propósitos da EP, a partir dos contributos freireanos, é o empoderamento das camadas populares com o intuito da transformação social. A EP busca criar mecanismos de poder para se contrapor à lógica opressora impressa pelas classes dominantes às oprimidas (BRANDÃO; ASSUMPÇÃO, 2009).

Esta EPF objetiva proporcionar por meio de práxis educativa uma formação qualitativamente diferenciada através de valores, finalidades, argumentos comprometidos com a descolonialidade, com a libertação. Reconhece e valoriza as formas próprias de aprender, fazer, viver das classes populares. E, Assim, contribui para a criação, consolidação e empoderamento de formas dife- 
rentes de organização popular (BRANDÃO, 1986). Pensar numa perspectiva crítica de EP é contrapor-se à ordem que comanda a lógica atual, e incluir procedimentos que superem a colonialidade.

O papeld@educador@popular,dentro desta dinâmica, apresenta uma característica qualitativamente diferenciada em relação às práticas que permeiam as formações tradicionais, pois porta-se como parceiro, interlocutor agente do diálogo.

A EP traz seu potencial dialógico nos modos de vivenciar a formação. Sai de uma postura conteudística sem cair no relativismo; centra-se no vivido para daí se alargar e se criticizar. Apresenta a mobilização popular na busca por alternativas para superar o sistema hegemônico. Busca a recomposição viável dos sonhos possíveis, da historicidade dos processos sociais, da politicidade inalienável dos atos educativos, tão distantes atualmente dos processos formativos hegemônicos. Visa o resgate das raízes fincadas no cotidiano, na cultura popular, na valorização dos saberes das classes populares e no aprimoramento da autoestima dos desprovidos de direitos.

No trato da EI, cabe ressaltar os contributos possíveis para o enfrentamento desse quadro social exposto acima, pois que um dos meios mais interessantes e adequados de viabilizar uma vereda no meio desse mundo opressor é potencializar uma dinâmica que coloque na pauta educativa a essencialidade das diferenças na tessitura dos saberes, dos conhecimentos necessários a um bem viver compartilhado no mundo que desejamos.

Comecemos a refletir acerca da Educação Intercultural por meio da problematização que significa incluir ou daquilo que predominantemente denominam de educação inclusiva. Seria a educação inclusiva um processo em que se amplia a participação 
de todos os estudantes nos estabelecimentos de ensino regular. Segundo alguns/algumas especialistas, trata-se de uma reestruturação da cultura, da prática e das políticas vivenciadas nas escolas de modo que estas respondam à diversidade de alunos. É uma abordagem humanística e democrática, que percebe o sujeito e suas singularidades, tendo como objetivos o crescimento, a satisfação pessoal e a inserção social de todos.

O próprio conceito de Incluir precisa ser avaliado. Incluir [Do lat. includere] traz um acerco de significados, tais como: compreender, abranger; conter em si; envolver, implicar; inserir, intercalar, introduzir; estar incluído ou compreendido; fazer parte; figurar, entre outro(s); pertencer, juntamente com outro(s). E podemos perguntar, em que se propõe a inclusão? Aonde se pretende incluir? O que significa excluir? Inclusão está associada ao sistema social vigente? Significa incluir no mercado? Bem, podemos optar por considerar a inclusão no campo dos que superam a opressão, portanto podemos considerar inclusão no contexto da humanidade crítica. Assim, a inclusão da Diferença que pode significar DIFERENTIGUAL, Intercultura, DIALÓGICA, dialogicidade.

Educação Intercultural seria assim uma educação que parte do reconhecimento recente da diversidade histórica étnico-cultural. Uma diversidade enraizada nas políticas de extermínio, escravização, deshumanização, inferiorização. E, assim, na suposta superação dos preconceitos sociais discriminatórios, hierarquizantes.

Lembremos que as verdadeiras relações são potenciais costuras de reconhecimento e inclusão, de acolhimento das demandas de povos ancestrais e de políticas multi-laterais. Decorrem disso importantes reflexões, tais como: a compreensão da interculturalidade crítica; a identificação da matriz da colonialidade global; 
a relação entre interculturalidade crítica e descolonialidade, vista desde o exemplo concreto da nova Constituição Equatoriana.

Os problemas com algumas perspectivas interculturais acríticas são: a ocultação ou minimização da conflitividade, dos contextos de poder e dominação; a limitação da interculturalidade ao contato (individual), deixando de lado o problema estrutural da sociedade. Até promove a convivência e a "tolerância" com metas para a inclusão (sem necessariamente tocar as causas da assimetria social e cultural). E desse modo, é meramente utilitária ou funcional para o sistema-mundo existente.

Por sua vez, a Interculturalidade Crítica parte do problema estrutural-colonial-racial e sua ligação com o capitalismo de mercado; questiona a lógica irracional, instrumental do capitalismo e aponta para a construção de sociedades diferentes e outros ordenamentos sociais; requer a transformação das estruturas, instituições e relações sociais e a construção de condições distintas de estar, ser, pensar, conhecer, aprender, sentir, y viver...

Portanto, podemos ensaiar uma definição para a INTERCULTURALIDADE CRÍTICA como sendo um processo e projeto político, ético e epistêmico, proposto inicialmente desde os movimentos indígenas da região andina, difundido pelos estudos da colonialidade, em particular por Catherine Walsh $(2008,2009)$. E desde sua perspectiva requer: transformar as atuais estruturas sociais e epistêmicas dessa sociedade; criar relações horizontais interétnicas através de novos ordenamentos sociais, políticos, epistêmicos e de existência; intenta superar com a história hegemônica de uma civilização, cultura e poder dominantes para construir relações, articulações e condições de poder, saber ser, viver distintas. 
A interculturalidade entendida criticamente ainda não existe, é um projeto utópico, u-topos, o não lugar enquanto lugar que ainda inexiste, mas pode vir a ser. É algo de múltipla via por tecer... E tecer uma interculturalidade crítica implica em transgredir, interromper, desmontar a matriz colonial e criar condições de poder, saber, ser, estar, viver que se distanciam do capitalismo e sua razão única

Tecer a descolonialidade implica em articular seres, saberes, modos e lógicas de viver; con-viver em uma nova ordem e lógica que parte da complementariedade, diferenças e reconhecimento das parcialidades sociais. Isto se associa a "Dialógica de saberes", na trilha do que indica Santos $(2008,2010)$ ao falar em Ecologia de Saberes que se contrapõe a sociologia das ausências que invisibilizam o que convém desaparecer do debate, das reflexões sociais, que negam os saberes do sul como abissais e bárbaros, sem valor epistêmico.

Neste conjunto reflexivo, reconheço a possibilidade de reafirmar que a epistemologia moderna tem oferecido justificativa para a negação dos saberes locais como relevantes para definir políticas e ações do estado. Ao mesmo tempo, encontro possibilidade para propor a articulação dialógica entre saberes múltiplos e conhecimentos científicos, que emergem como engajados com o popular, com a complexidade que nos oferece uma leitura ambiental dos tempos atuais.

E abrem-se as porteiras para um diálogo frutífero com a EA. E, embora existam inúmeras educações ambientais, escolhemos a Educação Ambiental Dialógica (EAD) que incorpora os pressupostos da EPF, uma pedagogia da Libertação, que se faz na superação de situações-limite, na direção do inédito viável.

A EAD é popular, crítica, política, com uma proposta de transformação sócio-ambiental. A Dialógica de Paulo Freire é seu grande eixo vital. Isto significa relação, partilha, trans-relacionali- 
dade. Relação que atravessa os que se relacionam na gestação de outros saberes.

A EAD entende o diálogo freireano como uma relação em que se consolida a práxis social transformadora que pretende o bem viver comum. A dialógica se dá numa estrutura dialética freireana. Nela gesta-se o entender desse quadro problemático que trata da viabilidade da vida no planeta.

Salienta que, na base das ações predatórias, situam-se representações de interesses de grupos minoritários, focando apenas seu interesse imediato, eliminando qualquer razão inerente ao outro subjugado. Foi assim que, na modernidade, a natureza passou a ser considerada uma coisa a serviço desses grupos concentradores das riquezas sociais.

$\mathrm{Na}$ EAD os temas geradores são problemas ambientais apontados pelos grupos envolvidos como situações-limite. Estes potencializam as leituras de mundo constituídas nos enfrentamentos e resistências sociais. Reafirmamos que muitos estudos ambientais têm se detido em análises conjunturais muito amplas, o que é relevante para os contornos concretos da questão. Entretanto, parece-nos importante traçar movimentos de compreensão sobre a interface entre o macro e o singular das culturas humanas e o modo como nelas se dá a percepção popular, enquanto elaboração da consciência ambiental. Afinal, o enraizamento local é que potencializa espraiar-nos mundo afora. "Ninguém se torna local a partir do universal. O caminho existencial é inverso." (FREIRE, 2001, p. 25).

Compreende-se que uma das relevâncias da EAD se define pela necessidade de se considerar os saberes populares e seu contexto de vida, ao contribuir com a potencialização dos movimentos populares, enquanto grupos-aprendentes nos embates sociais. 
Sua ênfase é na capacidade ontológica, própria do humano de 'ser mais', de superar as 'situações-limite', na direção de um 'sonho possível', por meio de um percurso que transita na direção de uma curiosidade epistêmica, crítica.

Destaco, ainda, que a politicidade do ato educativo, eixo da proposta freireana, é uma instância imprescindível na constituição de um 'quefazer' que, para além de mera palavra, é 'palavr-ação' transformadora do mundo, do ser, de si. Na relação o diálogo se faz existencial, com o sentido que se produz na práxis solidária. $\mathrm{Na}$ visão freireana, o humano é ser de relações plurais, por meio das quais se supera, humaniza-se, faz-se mais.

No processo de delimitação dos contornos de um diálogo entre a EA e a EP, ambas críticas, dialógicas e de matriz freireana, precisamos presentificar, corporificar, nessa práxis pedagógica, componentes como a solidariedade, a eqüidade, a participação crítica, a 'trans-ação', a práxis.

Aprender-educar dialogicamente exige o saber escutar amorosamente, pois é nessa escuta que se aprende a falar com @outr@ numa postura dialógica, considerando-@ também como ser de saber, autor@epistêmic@.Especialmente, exige se disponibilizar para o diálogo na valorização da diferença e na coerência entre o que se diz e se faz. Ensinar-dialogar exige querer bem aos educand@s, em uma amorosidade integrada a sua cognoscibilidade. Privilegia a sensibilidade, a abertura, ao bem querer, como elementos próprios da alegria necessária ao 'quefazer' docente.

Parece-nos que a interface privilegiada, entre EA e EP, se manifesta no e com o diálogo, como iniciação e consolidação do ciclo gnosiológico, ao constatar que a criticidade se dá na busca da razão de ser, que por meio da práxis transformadora que corporifica a curiosidade epistêmica, materializa a conscientizAção. 
Desse modo, contribui com o enfrentamento da ideia da representação ser identificada com a própria realidade. Re-inverte esse processo que consolida o conceito, as palavras ocas como o real, na busca do concreto pensado, da ação refletida, da palavra carregada de vida, das narrativas, dos causos, das metáforas como portadoras de vivências ricas do mundo d@s autor@s crític@s, atuantes e eco-relacionad@s. Retoma-se a relevância das relações contextualizadas e conscientes, dos vínculos essenciais que se pautam na solidariedade, e na essencialidade d@outr@ na constituição do 'ser mais' freireano.

\section{A Formação docente ambientalizada e descolonializada,} diante deste panorama, torna-se oportuna uma reflexão que favoreça uma análise crítica sobre a colonialidade/modernidade e suas implicações para a Formação d@ Educador@, bem como possibilitar contributos advindos da relação entre EA, EP e a EI.

Neste intuito, destacamos algumas características do contexto hegemônico de formação atual. Salientamos que neste âmbito também se expressa a crise da modernidade, em que é possível verificar a falta de uma preparação profissional adequada que contemple minimamente às demandas advindas das problemáticas da colonialidade/modernidade.

Os pressupostos de ensino-aprendizagem, nos programa de formação, são fundados em um modelo didático que traz a intervenção reguladora, que se contrapõe à experiência do presente, d@s autor@s envolvid@s, com vistas à uma preparação profissional para um futuro que, na maioria das vezes, existente somente no imaginário. @s professor@s ainda são considerados os principais detentores de um saber, saber erudito que desmerece os saberes populares; há uma intrínseca desvalorização d@s envolvid@s nas relações educativas. 
Os currículos dos cursos de formação são normativos; os saberes curriculares são trabalhados em disciplinas estanques (isoladas) que não dialogam entre si, nem potencializam problematizações; a fragmentação é um nuance constantemente presente em todas as esferas do processo de ensino-aprendizagem, o que favorece a excessiva parcialização e o esgarçar do conhecimento, o que torna até mesmo o 'cientista', o especialista em certo ramo, um ignorante especializado.

O paradigma dominante traz sempre a centralidade de algo, de uma única referência, com influência direta na formação humana e, por extensão, na formação docente; amplia a separação entre o conhecimento científico e os saberes contextualizados, do cotidiano, os saberes populares.

Sabemos que novas propostas se apresentam no contexto da formação de educador@s. Pesquisas que envolvem o trabalho com as histórias de vida dos professores, em sua interfase com a formação (NÓVOA, 1995); a prática reflexiva na reconfiguração das práticas pedagógicas (PIMENTA; GHEDIMN, 2002); a pesquisa na formação continuada e o professor como pesquisador de sua prática (ZEICHNER, 2002); a relação dos saberes e experiência para a formação e atuação docente (TARDIF, 2002), bem como discussões que apresentam novas tendências para a formação permanente (IMBERNÓN, 2009), são exemplos que demonstram a complexidade do tema.

Entretanto, consideramos pertinente pensar alternativas que possam contemplar uma leitura de formação mais identificada com os pressupostos da Educação Intercultural, da EP e da EA. Ou seja, pretendemos uma formação relacional, amorosa, politicamente intencionada na direção da descolonialidade, ambientali- 
zada nos movimentos em prol da sustentabilidade planetária e na solidariedade do bem viver compartilhado.

Neste intuito, propomos outras formas de perceber, planejar e fazer a formação de educador@s. Para tanto, nossa intenção se encaminha para um projeto de formação que se associa e se coaduna como os pressupostos da EPF e da EAD. Pressupostos que incluem a dialógica, o saber parceiro, a supra-alteridade e a amorosidade como eixos integradores para o processo de ensino. As múltiplas linguagens são ferramentas essenciais para valorização dos diferentes modos de compartilhamento dos conhecimentos. A contextualização é instância fundamental para a problematização e ambientalização do ensino. E por se tratar de um ensino ambientalizado acreditamos que o caminho desejável para a formação relacional é se fundamentar no diálogo entre EPF e EAD, intercultural por opção. Dessa maneira temos possibilidade para superação dos limites impostos pela modernidade/colonialidade, um caminho viável na práxis relacional dialógica.

O grande potencial dessa proposta de formação é a constituição de um diálogo que integra uma epistemologia, uma metodologia, uma ontogênese diferenciada por trazer como princípio a convivência solidária, democrática, sustentável com o lugar que habitamos. Isto, por sua vez, favorece a cooperação e autonomia entre aprendentes.

O maior desafio é manter a consciência de que, numa perspectiva descolonializante, há de se ter em alta conta o saber, o conhecimento, a lógica de outras leituras, escutas e sensibilidades. E nesta vertente, a dialógica relacional oferece contribuições importantes para a uma formação integrada na e para a transformação da realidade social, educacional, formativa, superando forma- 
ções bancárias, tecnicistas, cognitivistas elitistas, colonializantes, que des-humanizam.

A formação relacional traz a virtude de articular dimensões popular, ambiental, intercultural e amorosa de forma integrada, numa dinâmica favorecida por relações dialógicas. Esse modo de entender a formação de educador@s indica um caminho através do qual as relações se estabelecem em sintonia com os princípios da EPF e da EAD, portanto da EI. Assim, é concebida como potente para o enfrentamento dos padrões impostos pela colonialidade/ modernidade, ao levar em conta a interatividade relacional nos processos de ensino-aprendizagem.

Acreditamos que, ao propor a formação relacional de educador@s, demarcamos uma trajetória que define, como o próprio adjetivo indica, o relacional como eixo articulador, que se manifesta, essencialmente, no lugar em que aflora a amorosidade, a fé n@outr@, o diálogo autêntico, a tessitura de saberes em parceria, a busca de resolução das questões sócio-ecológicas integradas a uma percepção local-global.

A formação relacional principia com a constituição de grupos-aprendentes, compostos por 'autor@s epistêmic@s', ensinantes e aprendentes simultaneamente. Não há hierarquização, nem quem sabe mais ou menos. Há valorização de todos os saberes e conhecimentos, no reconhecimento de suas diferenças intrínsecas como riqueza. Assim, tod@s podem se sentir incluíd@s, valorizad@sem suas peculiaridades, respeitad@s em suas diferenças; parceiros de aprendizagem dentro de uma dinâmica interativa e dialogal.

A formação, quando tecida de forma relacional e ambientalmente contextualizada, privilegia uma dinâmica que se estabelece por meio do diálogo e do compartilhamento de experiências, 
em todos os níveis de socialização, elaboração e corporificação de conhecimentos e saberes de modo intercultural crítico.

A dialógica permite ainda que a amorosidade aflore na constituição da teia relacional, na efetivação dos laços de confiança, de respeito e cuidado mútuo. $\mathrm{O}$ sentimento de pertença a um grupo potencializa que se supere o individualismo no partilhar com @ outr@. É na dimensão amorosa que encontramos a motivação e o estímulo para a ação e a comunicação, bem como para a potencialização da autoestima na práxis que favorece o reconhecimento da capacidade de transformar uma dada realidade.

Têm-se, desse modo, uma formação crítica e democrática, numa lógica que ultrapassa e enfrenta os desafios contemporâneos e opta por uma educação comprometida com @s oprimid@s, numa perspectiva popular; na relação dialética entre teoria e prática, bem como uma fundamentação crítica e comprometida com a descolonialidade, com a transformação social que pretende $\mathrm{o}$ bem viver compartilhado.

A formação relacional popular ambientalizada, intercultural, crítica, busca superar a lógica e os alicerces desse quadro societário hegemônico, dessa sociedade capitalista, dessa modernidade e, do seu lado oculto, a colonialidade. Portanto, formação relacional implica em uma dinâmica popular que integra a ambientalização ao seu ser-fazer. Esta FormAção afirma uma relação dialógica entre a EA Paulofreireana e a EAD; está encharcada de uma educação politicamente pautada para enfrentar os dilemas contemporâneos, para potencializar a 'des-colonialidade'.

Nas conclusões deste artigo, retomamos termos como reflexão, ação, dialogação na experiência descolonializante; no buscar, perceber, desvelar e realizar. Cabe salientar a pertinência das propostas que aqui formulamos por contribuir efetivamente com outra 
prática identificada com saberes esquecidos na modernidade, com saberes desconhecidos na colonialidade, com saberes imprescindíveis a um mundo melhor, mais solidário, equânime e comprometido com um bem viver costurado e compartilhado por todos.

Salientamos que a descolonialização educativa implica num amplo processo de desvelar procedimentos que alienam o conhecimento. Em geral, os processos educativos hegemônicos contribuem com a colonialização ao reforçar posturas autoritárias, que hierarquizam e definem um campo de poder desigual e pré-definido. Muitas vezes o padrão educativo dominante ganha força através de detalhes, tal como quando há uma rejeição ao erro d@ outr@, aos limites, a ignorância.

$\mathrm{Na}$ educação a micro-colonialidade se materializa através de um mecanismo excludente, autoritário, arbitrário, elitista, cognitivista. Há uma aura de superioridade decorrente do 'domínio' de um conhecimento acadêmico. Nesta lógica, se des-humanizam as pessoas que desconhecem o que conhecem os opressores. Age-se com violência autoritária diante do que é qualificado de insubordinação, indisciplina ou descaso.

É urgente uma formação relacional que possa contribuir com a necessária vigilância epistemológica diante das posturas colonializantes de que somos capazes, por habitar em nós o opressor enquanto somos inconscientes dessa possibilidade. É preciso nos libertamos da opressão, da colonialização para que possamos contribuir com a libertação do outr@.

É possível uma postura descolonializante no trato da educação, do ensino. Somos capazes de manifestar respeito, estabelecer relações educativas horizontais, dialógicas e por isso mesmo relações pautadas na amorosidade. A descolonialidade do ensinar frutifica na árvore da amorosidade, do respeito, do 
cuidado, dahumildade. Arar, semear, regar, adubareassim colher o fruto. $\mathbf{O}$ afago da terra, de quem conhece os desejos da terra. E, no cio da terra fecundar o chão. Debulhar o trigo e com o trigo gerar o milagre do pão. Assim podemos comungar.

\section{Referências}

AZIBEIRO, Nadir Esperança. Relações de saber, poder e prazer: educação popular e formação de educadores. Florianópolis, SC: Cepec, 2002.

BAWMAN, Zygmunt. Modernidade líquida. Trad. Plínio Dentzien. Rio de Janeiro: Jorge Zahar, 2001.

BRANDÃO, Carlos R. O que é educação popular. São Paulo: Brasiliense, 1986.

; ASSUMPÇÃO, Raiane. Cultura rebelde: escritos sobre a educação popular ontem e agora. São Paulo: Instituto Paulo Freire, 2009. (Educação Popular).

CARRILO, Alfonso T. La educación popular: trayetoria y atualidad. Bogotá: El Buho, 2007.

CORONIL, Fernando. Natureza do pós-colonialismo: do eurocentrismo ao globocentrismo. In: LANDER, E. (Org.). A colonialidade do saber: eurocentrismo e ciências sociais. 1. ed. Buenos Aires: Consejo Latinoamericano de Ciências Sociales - CLACSO, 2005.

DELEUZE, G. Conversações. Rio de Janeiro: 34, 1992.

FIGUEIREDO, J. B. A. Educação Ambiental Dialógica: as contribuições de Paulo Freire e a Cultura Sertaneja Nordestina. Fortaleza: UFC, 2007.

FREIRE, Paulo. A sombra da mangueira. 4 ed. São Paulo, SP: Olho d'água, 2001. 
1983.

Pedagogia do oprimido. 13 ed. Rio de Janeiro: Paz e Terra,

FOCAULT, Michel. Vigiar e punir. Petrópolis, RJ: Vozes, 1989.

IMBERNÓN, Francisco. Formação permanente do professorado: novas tendências. São Paulo: Cortez, 2009.

LANDER, Edgardo. Ciências sociais: saberes coloniais e eurocêntricos. In: LANDER, E. (Org.). A colonialidade do saber: eurocentrismo e ciências sociais. $1^{\text {a }}$. ed. Buenos Aires: Consejo Latinoamericano de Ciências Sociales - CLACSO, 2005.

LIPOVETSKY, G. Os tempos hipermodernos. São Paulo: Barcarolla, 2004.

MIGNOLO, Walter D. A colonialidade de cabo a rabo: o hemisfério ocidental no horizonte conceitual da modernidade. In: LANDER, Edgardo (Org.). A colonialidade do saber: eurocentrismo e ciências sociais. 1. ed. Buenos Aires: Consejo Latinoamericano de Ciências Sociales - CLACSO, 2005.

NÓVOA, A. (Org.). Os professores e sua formação. Lisboa: Dom Quixote, 1995.

PIMENTA, S. G.; GHEDIMN, E. (Orgs.). Professor reflexivo no Brasil: gênese e crítica de um conceito. São Paulo: Cortez, 2002.

QUIJANO, Aníbal. Colonialidade do poder. Revista 'Perú Indígena', Lima, v. 13, n. 29, p.11-20, 1991.

. Colonialidade do poder, eurocentrismo e América Latina. In:

LANDER, Edgardo (Org.). A colonialidade do saber: eurocentrismo e ciências sociais. 1. ed. Buenos Aires: Consejo Latinoamericano de Ciências Sociales - CLACSO, 2005.

SANTOS, Boaventura de Sousa. A gramática do tempo: para uma nova cultura política. 2. ed. São Paulo, SP: Cortez, 2008. (Coleção para um novo senso comum, v. 4). 
Para além do pensamento abissal: das linhas globais a uma ecologia de saberes. In:

SANTOS, B. S.; MENEZES, M. P. Epistemologias do sul. São Paulo: Cortez, 2010.

TARDIF, Maurice. Saberes docentes e formação profissional. Petrópolis, RJ: Vozes, 2002.

WANDERLEY, L. Eduardo W. Educação popular: metamorfoses e veredas. São Paulo: Cortez, 2009.

WALSH, Catherine. Interculturalidad, plurinacionalidad y decolonialidad: las insurgencias político-epistémicas de refundar el Estado. Tabula Rasa, Bogotá, n. 9, p. 131-152, julio-diciembre 2008. (Tradução livre de João B. A. Figueiredo, 2008).

. Interculturalidad, estado, sociedade: luchas (de)coloniales de nuestra época. Quito, Equador: Universidade Andina Simón Bolívar/ Ediciones Abya-Yala, 2009.

ZEICHNER, Kenneth M. A pesquisa na formação e no trabalho docente. Belo Horizonte: Autêntica, 2002.

\section{Notas}

* Pós-Doutorado em Educação, doutor em CIências, professor associado da Faculdade de Educação da Universidade Federal do Ceará e professor do PPGEB da UFC. E-mail: <joaofigueiredoufc@gmail.com>.

** Pós-Doutorado em Educação, doutor em Clências, professor associado da Faculdade de Educação da Universidade Federal do Ceará e professor do PPGEB da UFC. E-mail: <joaofigueiredoufc@gmail.com>.7

${ }^{1}$ Com o “@” utilizamos simultaneamente os gêneros feminino e masculino. Ao invés de usar os substantivos e complementos nominais no masculino, gramaticalmente correto, utilizamos este símbolo para levantar a questão política e cultural do sexismo de nossa linguagem. 